\title{
usm

\section{Recriações de papéis sociais sobre família no brincar de crianças pequenas}

\author{
Recreation of social roles about family in children's play
}

\section{* Rafaely Karolynne do Nascimento Campos}

Doutoranda na Universidade Federal de Sergipe, São Cristóvão, Sergipe, Brasil. rafakarolynne@yahoo.com.br

\section{** Tacyana Karla Gomes Ramos}

Professora doutora na Universidade Federal de Sergipe, São Cristóvão, Sergipe, Brasil. tacyanaramos@gmail.com

Recebido em 27 de setembro de 2018 Aprovado em 17 de junho de 2019

Publicado em 11 de setembro de 2019

\section{RESUMO}

O presente estudo pretende analisar a rotina de brincadeiras de papéis sociais sobre relações familiares que as crianças empreendem em suas interações com parceiros de idade no contexto da Educação Infantil. Participaram da pesquisa 25 crianças, com trinta e seis meses de idade, integrantes de uma instituição municipal de Educação Infantil. Os dados foram produzidos por meio da perspectiva etnográfica, através de observações, filmagens e registros em notas de campo dos momentos de brincadeiras de livre escolha das crianças no parquinho, na brinquedoteca e durante atividades não direcionadas pelo adulto, dentro da sala de referência do grupo. Do conjunto de 102 cenas interativas analisadas, no intuito de fornecer suportes empíricos à discussão, foi escolhido o episódio "Dois pais" para dar visibilidade aos achados e por apresentar aspectos considerados relevantes para o alcance do objetivo central elencado para o presente trabalho. Os resultados do estudo comprovam que, em situações de brincadeiras com pares de idade, as crianças constroem, negociam e compartilham significados, indicando compreensões de relações e de papeis sociais desempenhados no contexto familiar, sinalizando fragmentos perceptivos/interpretativos a respeito desse contexto social.

Palavras-chave: Brincadeira; Culturas da Infância; Família. 


\section{Autตaดูão}

ISSN: 1984-6444 | http://dx.doi.org/10.5902/1984644434956

\section{ABSTRACT}

This study analyzes the routine that children undertake in their interactions with sameage partners in the context of Child Education, playing social roles about family relationships. 25 children, with thirty-six months of age, participated in the study. They are members of a Brazilian municipal institution of Early Childhood Education. The data were produced from an ethnographic perspective, based on observations, video recordings and field notes of children's free play in the playground, in the toy library, and during activities not directed by an adult, inside the reference room of the group. From a set of 102 interactive scenes analyzed, to provide empirical support for the discussion, the episode named "Two Fathers" was chosen to give visibility to the findings and to present parts considered relevant for the achievement of the main purpose of this study. Our results show that children, with same-age partners, play, negotiate, and share meanings, indicating understandings of relationships and social roles played in the family context, signaling perceptual/interpretative fragments regarding this social context.

Keywords: Child's play; Cultures of childhood; Family.

\section{O brincar com lugar privilegiado de (re)criações culturais}

O brincar tem sido considerado como a forma privilegiada de participação das crianças na cultura. Diferentes estudos confirmam a ideia de que a criança interpreta ideias, concepções, valores e expectativas de determinados papéis desempenhados socialmente em ocasião de brincadeiras com pares de idade (cf., por exemplo, CORSARO, 2009a; FERREIRA, 2004; BORBA, 2005; LUCENA; PEDROSA, 2014; PEREIRA; LIRA; PEDROSA, 2011; SANTOS, 2015).

Tais investigações vêm ressaltando a relevância do brincar e suas interfaces com as relações sociais entre pares de idades, desvendando aspectos inovadores e criativos da participação das crianças em questões da sociedade que ela observa e interage. Brincando, a criança revela aspectos de sua compreensão, apropria-se de informações e as reproduz, especialmente nos jogos de faz de conta, a partir da experimentação de "personagens" (OLIVEIRA, 2011).

Nesse sentido, a brincadeira de faz de conta pode ser reconhecida como espaço social da experiência que permite a criança participar de uma situação inventada como se fosse real e, assim, protagonizar diferentes papéis sociais 


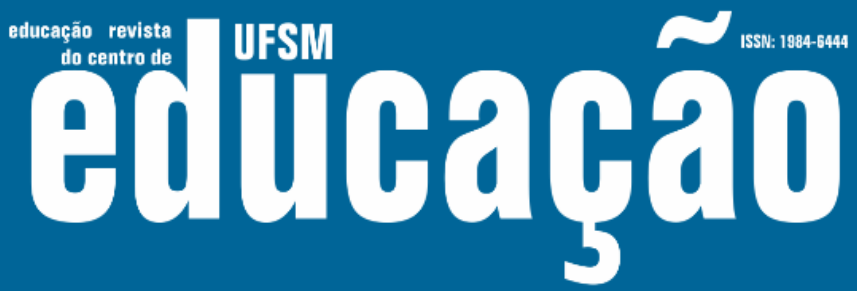

ISSN: 1984-6444 | http://dx.doi.org/10.5902/1984644434956

encontrados na macrocultura, recriando as informações do ambiente cultural, em seus enredos lúdicos compartilhados com parceiros de idades, conforme suas compreensões (OLIVEIRA, 2011).

Nessa trilha de proposições, as crianças se engajam num processo de interpretação do mundo social, das pessoas e de si mesmos, em situações de brincadeiras compartilhadas com companheiros de idade, através do processo de reprodução interpretativa (CORSARO, 2011).

Corsaro (2009a, 2011) apresenta contribuições relevantes ao propor o conceito de reprodução interpretativa como uma crítica à teoria da socialização proposta pela psicologia do desenvolvimento e pela concepção durkheimiana, apresentando na contramão dessas premissas teóricas a perspectiva de que as crianças não se limitam a reproduzir os valores e as normas que os adultos the transmitem, mas os reinterpretam de forma criativa e renovada em situações interativas, particularmente durante o brincar.

A proposta do referido autor é apresentar uma nova ideia de socialização, valorizando a participação coletiva das crianças a partir de um movimento de produção e reprodução de sua própria cultura e na participação das culturas societais. Sendo assim, em substituição ao conceito tradicional de socialização, Corsaro (2009a) esclarece que tal processo é interpretativo, pois "as crianças criam e participam de suas próprias e exclusivas culturas de pares quando selecionam e se apropriam criticamente de informações do mundo adulto para lidar com suas próprias e exclusivas preocupações". A noção de reprodução "inclui a ideia de que as crianças não se limitam a internalizar a sociedade e a cultura, mas contribuem ativamente para a produção e mudanças culturais" (CORSARO, 2009a, p. 31-32, grifos do autor).

Nesse sentido, a reprodução interpretativa é dos elementos centrais da teoria de Corsaro e esse conceito vem contribuindo para as reflexões acerca da cultura de pares, definida "como um conjunto estável de atividades ou rotinas, artefatos, valores e interesses que as crianças produzem e compartilham na interação com seus pares" (CORSARO, 2009a, p.32). O referido autor apresenta as culturas infantis como estruturantes do cotidiano das crianças, em processo produzido e partilhado através da experiência social, revelando-se nos modos de sentir, agir, pensar e interagir com 


\section{F HEM

ISSN: 1984-6444 | http://dx.doi.org/10.5902/1984644434956

mundo e com os sujeitos que as crianças empreendem ativamente.

Sarmento (2003, 2002) compreende que as culturas da infância são integralizadas pelas brincadeiras das crianças como também pelos modos específicos de ser e de se comunicar dos grupos de pares de idade. O autor compreende também o brincar como um dos pilares das culturas da infância e defende a ideia de que as culturas infantis são culturas de pares, ou seja, agindo coletivamente, as crianças vão se constituindo enquanto ser social, criando seus próprios modos de ser e agir no mundo e desenvolvem o sentimento de pertencimento ao grupo.

Ampliando o argumento exposto, Corsaro (2011) explica que na brincadeira conjunta, as crianças produzem uma variedade de rotinas, cujo objetivo central é fazer coisas em conjunto. Segundo o autor, as rotinas são práticas sociais subordinadas às regras e normas instituídas pelas crianças que organizam e regulam as ações do grupo de pares em situações interativas.

Borba (2005) aponta as rotinas de brincadeiras como uma sequência de comportamentos previsíveis e que apresentam a preferência das crianças, repetindose com frequência e com consistência. Ferreira (2004, p. 62) contribui afirmando que as rotinas favorecem para "[...] tornar aquele mundo familiar, comunal, recorrente, previsível; por isso mesmo, objectos de intervenções discursivas e práticas, inovadoras e criativas, que o tornam altamente flexível, adaptável e transformável [...].

A brincadeira de casinha pode ser considerada como uma extensão cultural da sociedade, trazendo práticas sociais domésticas familiares para as ações lúdicas das crianças em situações compartilhadas (BORBA, 2005). Nesse sentido, reconhecemos que o papel da atividade lúdica pode ser considerado como um rico contexto que dá suporte para a criança (re)criar múltiplas perspectivas sobre os eventos sociais de seu tempo, como também serve de espaço para (re)produção do sistema pelo viés interpretativo da criança.

Diante de tais considerações, este trabalho compreende o brincar como uma prática social e cultural, na qual as crianças constroem e compartilham relações sociais, novos significados, formas individuais e coletivas de interpretar o mundo, enfatizando-se a agência das crianças nas suas relações com seu contexto social. Logo, adota a perspectiva teórica que reconhece as crianças como "[...] agentes 


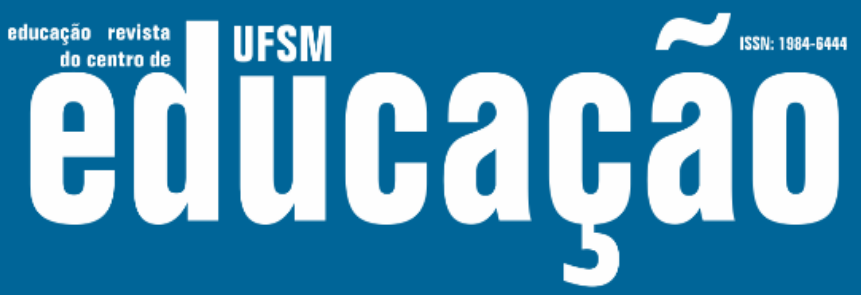

ISSN: 1984-6444 | http://dx.doi.org/10.5902/1984644434956

sociais, ativos e criativos, que produzem suas próprias e exclusivas culturas infantis" (CORSARO, 2011, p.15).

Embora seja inegável a potência criativa que a criança possui para (re)inventar e (re)significar suas experiências sobre a sociedade e a produção cultural, concordamos com Cohn (2005, p.37) quanto ao alerta para a "relativa autonomia cultural das crianças, pois estas compartilham com os adultos um sistema simbólico a partir do qual dão sentido às experiências e constroem suas culturas".

O presente estudo é um recorte de uma pesquisa de mestrado já concluída e pretende analisar a rotina de brincadeiras de papéis sociais sobre relações familiares, que as crianças de trinta e seis meses empreendem em suas interações com parceiros de idade no contexto da Educação Infantil.

\section{Itinerários de geração dos dados}

Dentre os distintos contextos que a criança faz parte, escolhemos a Educação Infantil como locus para a presente investigação. O estudo foi realizado numa instituição municipal de Educação Infantil localizada em Aracaju/SE, com um grupo de 25 crianças, de ambos os sexos, com trinta e seis meses de idade, integrantes do agrupamento etário denominado de Infantil IIIB.

Utilizamos o termo geração e não coleta de dados, baseada em Graue e Walsh (2003, p.115) que ressaltam que "os dados não estão por aí à nossa espera" para a coleta, mas surgem das relações e interações que o pesquisador estabelece com o campo de pesquisa, de modo que um dado tem muitas possibilidades de interpretação, dependendo do olhar do pesquisador. No viés dessa consideração, buscamos aportes teóricos e metodológicos que permitissem a geração de dados capazes de retratar os modos como as crianças brincam sem um roteiro préestabelecido para análise.

Para alcançar os objetivos elencados para o presente estudo foram utilizados os procedimentos metodológicos da pesquisa etnográfica: observação participante com anotações em diário de campo, fotografias e gravações em vídeo das brincadeiras de livre escolha realizadas pelas crianças nos momentos de recreação 


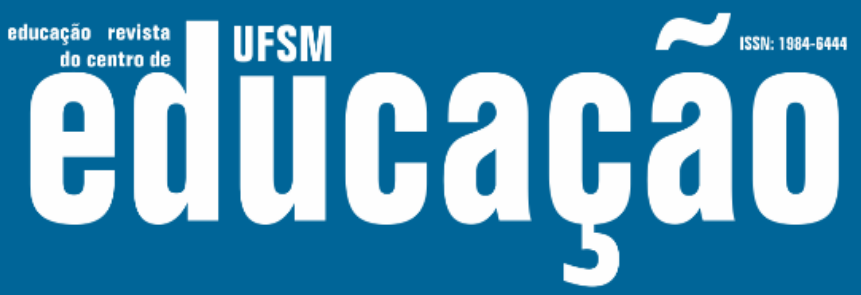

ISSN: 1984-6444 | http://dx.doi.org/10.5902/1984644434956

(espaços do parquinho e na brinquedoteca) e durante as atividades não direcionadas pelo adulto, realizadas na sala de referência do grupo participante.

A observação participante foi realizada durante os meses de fevereiro a junho de 2016, com idas à instituição de três a cinco vezes na semana, com duração de permanência no contexto do estudo entre três a quatro horas por dia.

A observação participante possibilitou a captura de diversas situações da vida social e cultural vivenciada pelo grupo de crianças investigado nas ocasiões de brincadeiras, sem um roteiro fixo para as observações. O diário de campo permitiu o registro reflexivo sobre as brincadeiras dos grupos de pares, bem como os diálogos, as interações e as relações sociais estabelecidas entre as crianças e que foram revisitadas e transcritas para o computador, após cada dia de observação.

As gravações audiovisuais puderam apreender grande quantidade de dados descritivos acerca das relações e interações ocorridas nas práticas sociais e culturais das crianças nos modos e processos de brincar. Do conjunto das cenas videogravadas, foram selecionados e descritos episódios interativos que apresentassem aspectos pertinentes aos objetivos elencados para o presente estudo. As cenas interativas alçadas das filmagens foram transcritas e elaboradas por meio da análise microgenética (PEDROSA; CARVALHO, 2005).

Para fins de construção de dados, também foram extraídas fotografias sequenciadas dos vídeos, através de um programa de computador de domínio público, disponível na internet, chamado Free Vídeo To JPG Converter. A geração dos dados baseou-se na combinação entre reflexões produzidas pela análise das transcrições dos vídeos, de releituras das notas de campo e também por meio das fotografias empreendidas. Os dados produzidos foram agrupados em unidades de sentido, resultando nas categorias apresentadas no quadro a seguir: 


\section{F Fs" Guthagãó}

ISSN: 1984-6444 | http://dx.doi.org/10.5902/1984644434956

Quadro 1 - Unidades de Sentido e Categorias para geração dos dados

\begin{tabular}{|c|c|}
\hline UNIDADES DE SENTIDO & CATEGORIAS \\
\hline Brincadeiras & Rotinas de Brincadeiras \\
\hline \multirow{2}{*}{ Formação de Grupos } & Amizade e o brincar junto \\
\cline { 2 - 2 } & Estratégias de acesso e formas de resistência \\
\cline { 2 - 2 } & Gênero \\
\hline \multirow{2}{*}{ Relações Sociais } & Ciderança \\
\cline { 2 - 2 } & Conflitos \\
\cline { 2 - 2 } & Cooperação \\
\hline
\end{tabular}

Fonte: Elaborado com base nos registros da pesquisa.

Do conjunto de material produzido, a pesquisa findou com 119 horas de observação participante, 14 horas de videogravações, 344 fotografias (69 fotos da creche, 252 fotos das crianças em atividades de brincadeiras e 23 fotos registradas pelas próprias crianças) e 28 registros no diário de campo com 40 páginas de anotações.

Cabe informar que o estudo foi aprovado pelo Comitê de Ética, cujo protocolo foi registrado sob número CEP/CCS/UFS/ CAAE ํํ 51979915.2.0000.5546 e realizado com autorização da Secretaria Municipal de Educação, o consentimento da Direção e professora da instituição, bem como o consentimento dos pais ou responsáveis pelas crianças, mediante o Termo de Consentimento Informado.

Obter o consentimento da direção, professores, pais e responsáveis pelas crianças não foi o desafio maior a ser enfrentado na pesquisa. O mais instigante foi receber a autorização das crianças participantes da pesquisa, consideradas coautoras do processo de investigação. Alderson (2005) contribui nesse sentido afirmando que a autorização dos diretores, professores e responsáveis pelas crianças não é suficiente. As crianças precisam autorizar sua participação na pesquisa e isso não se dá com uma assinatura do papel.

Imbuídas de tais considerações e contribuições dos estudos sociais da infância e os aportes teórico-metodológicos eleitos para o presente estudo, buscamos nos 


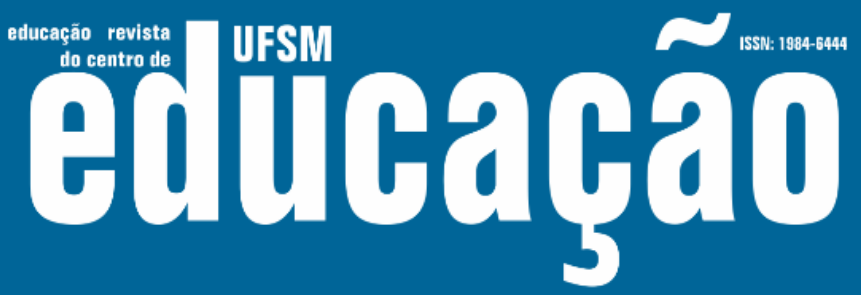

ISSN: 1984-6444 | http://dx.doi.org/10.5902/1984644434956

aproximar socialmente do grupo de crianças de forma processual. Procuramos estar atentas as múltiplas linguagens das crianças, às suas reações quanto à nossa presença, entendendo que em todo o percurso da pesquisa, seria um movimento de negociação da nossa presença nos seus universos. Graue e Walsh (2003) contribuem nesse sentido afirmando que,

O comportamento ético está intimamente ligado à atitude - a atitude que cada um leva para o campo de investigação e para a sua interpretação pessoal dos factos. Entrar na vida das outras pessoas é ser-se um intruso. É necessário obter permissão, permissão essa que vai além da que é dada sob formas de consentimento. É a permissão que permeia qualquer relação de respeito entre as pessoas. (GRAUE e WALSH, 2003, p.76)

Corroboramos com as ideias de Spink (2000) ao afirmar que a ética na pesquisa é uma ética dialógica, caracterizada pela capacidade de interação do pesquisador com os pesquisados, nesse caso, as crianças. A ética da pesquisa parte dessa relação e não da ética instituída por documentos, autorizações e permissões.

O processo dialógico entre pesquisador e sujeitos da pesquisa deve ser construído ao longo da investigação. As formas de se incluir as crianças como coparticipantes na condução da pesquisa baseiam-se na explanação dos objetivos e dos procedimentos do estudo a serem executados pelo pesquisador e na escuta das vozes das crianças em todo o processo de investigação. É essa escuta que permite ao pesquisador ganhar a confiança das crianças e se tornar um membro do grupo, favorecendo que elas também se constituam como participantes e coautores da pesquisa.

$\mathrm{Na}$ experiência de pesquisa, percebe-se que a busca do diálogo com as crianças, mais do que um princípio metodológico consistiu em um princípio ético dialógico entre pesquisador e sujeitos da investigação, levando a assegurar que as vozes e as identidades desses sujeitos fossem respeitadas e evidenciadas na pesquisa.

Um dos pressupostos da pesquisa etnográfica é que o pesquisador deve tornarse como um nativo, buscando interação, envolvimento e proximidade com o contexto e com seus participantes, tornando-se semelhante aos sujeitos da investigação. 


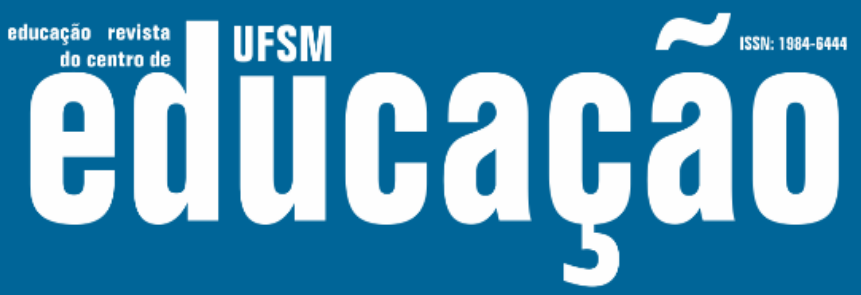

ISSN: 1984-6444 | http://dx.doi.org/10.5902/1984644434956

Sendo assim, como estar com as crianças sem deixar de ser uma adulta? Que papel assumir como pesquisadora? Diante da necessidade de aproximação do mundo social das crianças, optamos por adotar a postura de um adulto diferente daquele que fiscaliza. Logo, assumir esse papel implicou estabelecer uma relação com as crianças diferente dos outros adultos que se relacionavam diariamente com elas, destituído de poder e autoridade.

Assim, houve investimentos no modo cuidadoso de penetrar no contexto social das crianças com sensibilidade e, principalmente, com o desprendimento da visão adultocêntrica, na busca por estabelecer uma relação de aceite e confiança por parte delas. Buscamos adentrar nas rotinas dos sujeitos investigados, participando das atividades quando convidadas pelas crianças ou adotando uma postura de quem respeitosamente solicita permissão para participar de suas rotinas, não sendo invasiva, com o objetivo de evitar desconforto ao grupo.

Nesse posicionamento de uma atitude não invasiva por parte do pesquisador, as crianças vão agregando esse "novo amigo" (FINE \& SANDSTROM, 1988 apud BORBA, 2005), permitindo a sua participação nas atividades e introduzindo-o no grupo de pares de idade. Logo, à medida que adentrava nas rotinas das crianças, a pesquisadora pode ir percebendo que o status de participante ia sendo estabelecido.

Tais procedimentos se alinham aos fundamentos de Corsaro (2009b) quando defende a ideia de que a investigação etnográfica envolve a entrada do pesquisador no campo de forma gradual, aceitação dele pelo grupo social e consequentemente o estabelecimento do status de participante no grupo de sujeitos da pesquisa.

Após adquirir o status de participantes e sermos aceitas pelo grupo, buscamos inserir junto ao grupo de crianças os instrumentos que permitissem a geração de dados capazes de retratar os modos como elas brincavam. Por se tratar de uma pesquisa que buscava retratar o modo como as crianças brincavam, consideramos necessário o uso da imagem, da fotografia ou da filmagem na pesquisa, pois tais instrumentos são capazes de apreender o fenômeno em movimento e obter grande quantidade de dados descritivos acerca das relações e interações ocorridas nas práticas sociais e culturais das crianças nos processos de brincar. Entretanto, em determinados contextos de pesquisa é necessário discutir em que medida o uso de 


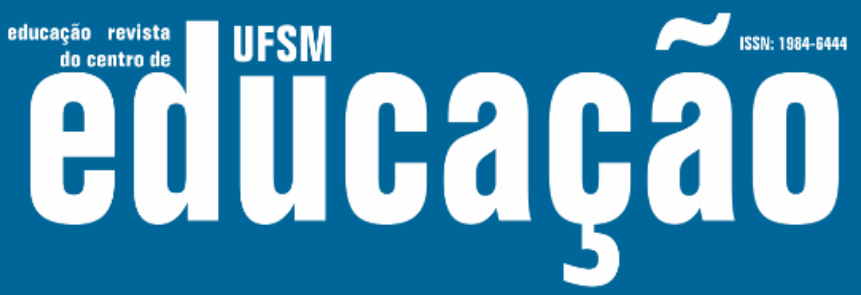

ISSN: 1984-6444 | http://dx.doi.org/10.5902/1984644434956

imagens e filmagens é realmente imprescindível, uma vez que tem sido comum o uso gratuito e uma banalização de imagens em certas pesquisas.

Em relação ao uso de imagens, buscamos analisá-las, tendo o cuidado de não expor negativamente as crianças. No que diz respeito ao anonimato do nome da criança, há que se ter também o cuidado e essa foi uma das principais situações que nos deparamos: a utilização ou não dos nomes das crianças na pesquisa. Nesse sentido, Kramer (2002) contribui apontando que:

Quando trabalhamos com um referencial teórico que concebe a infância como categoria social e entende as crianças como cidadãos, sujeitos da história, pessoas que produzem cultura, a ideia central é a de que as crianças são autoras, mas sabemos que precisam de cuidado e atenção (KRAMER, 2002, p.42).

Tendo em vista que os dados gerados na pesquisa não apresentaram situações que denigriam e/ou expunham negativamente a imagem das crianças e tratando-se de uma pesquisa que se fundamenta nas concepções de crianças como autoras sociais e produtoras de culturas, não negamos suas identidades, suas condições de sujeitos e nem escondemos a autoria de suas ações (KRAMER, 2002), utilizamos os nomes verdadeiros das crianças participantes da investigação. Nesse contexto, a escolha de revelar ou não os nomes das crianças envolvidas na pesquisa esteve ancorada na discussão sobre autoria e anonimato. Na pesquisa em tela considerouse importante identificar o sujeito e revelar sua autoria, porque isso não oferecia riscos às crianças.

Noutra esfera de argumentação, durante o processo da investigação, foi possível identificar, mapear e caracterizar algumas rotinas de brincadeiras que se apresentaram com mais frequência nos grupos de pares do contexto investigado, tais como a rotina de brincadeiras de papéis sociais envolvendo relações familiares. Tais brincadeiras possuíam diversos scripts do contexto cultural cotidiano: preparação de alimentos, cuidados com a casa, lavar e passar roupas, tomar banho, ir ao trabalho fora de casa, realizar festas de aniversário, namorar, casar-se, maquiar-se e/ou maquiar a filha/amiga, dentre outras.

Cabe ressaltar que os dados gerados no presente estudo destacam que a rotina de brincadeira de relações familiares, envolvendo os scripts associados a ela, foi 


\section{Autuaŗão}

ISSN: 1984-6444 | http://dx.doi.org/10.5902/1984644434956

apontada como uma das preferidas das crianças, revelando-se em 102 cenas analisadas na pesquisa.

No intuito de fornecer suportes empíricos à discussão, foi escolhido o episódio "Dois pais", extraído do banco de dados gerados, por apresentar aspectos considerados relevantes para o alcance dos objetivos elencados para o presente trabalho e para ilustrar a análise de como, em situações de brincadeiras, as crianças constroem, negociam e compartilham significados, indicando compreensões de relações e de papéis sociais desempenhados no cotidiano familiar, alçados da macrocultura. $\mathrm{O}$ episódio eleito traz situações nas quais as sequências de ações das crianças são orientadas pelo enquadre de brincadeiras de casinha, conforme apresentaremos a seguir.

\section{Brincando de casinha e (re)criando papéis sociais sobre relações familiares}

Durante as observações, percebemos a preferência das meninas quanto ao tema de brincadeiras de casinha, o qual está vinculado à representação social do gênero feminino, relacionadas às atividades domésticas e papéis sociais tradicionalmente atribuídos ao universo feminino. Alguns meninos também participaram desse tipo de brincadeiras, assumindo os papéis de pai, de filho, de irmão.

Outro ponto que observamos nas ações do brincar no grupo, diz respeito às atividades desempenhadas pelas crianças enquanto personagens de uma brincadeira de casinha. Em cada um dos episódios selecionados sobre o tema, foi possível observar os distintos membros da "família brincada" envolvidos em alguma atividade que pareciam compor o enredo da ação lúdica na medida em que ganhava desdobramentos a partir das interações então estabelecidas.

No conjunto de cenas analisadas, observamos que a maioria das brincadeiras de casinha foram iniciadas com a utilização de objetos disponibilizados pelo adulto para as crianças, seguida pela proposta-convite iniciada por alguma criança por meio de perguntas indicadoras do enredo da brincadeira: "vamos brincar de mãe e filha?" 


\section{Ailloapẫ}

ISSN: 1984-6444 | http://dx.doi.org/10.5902/1984644434956

ou "vamos brincar de casinha?". Em seguida, com a aceitação da proposta pelos parceiros, na maioria das vezes, a criança que sugeriu a brincadeira designava os papéis dos integrantes, como por exemplo: "eu sou a mãe, você é a filha" ou "eu sou a filha e você é a mãe". Em algumas poucas situações, as crianças iam escolhendo os papéis que desejam assumir na brincadeira, sem necessidade de determinação daquela criança que sugeriu a brincadeira.

Vejamos o episódio ${ }^{1}$ a seguir para dar prosseguimento aos argumentos apresentados.

Episódio: Dois pais

Local: Sala de referência

Duração: 05min $25 \mathrm{seg}$

Data: 06/04/2016

Crianças envolvidas: Kethely, Ruan, Guilherme, Cristofer, Sibele.

Kethely e Ruan montam uma casinha com as cadeiras que estavam disponíveis na sala. Ruan e Kethely sentam dentro da casa, quando Guilherme se aproxima.

Ruan: Eu sou o papai e ela é a mãe (apontando para Kethely).

Ruan olha para Kethely e pergunta: Eu sou o pai, né?

Kethely diz para Guilherme: você é o filho.

Guilherme: Não, eu sou... (...) eu sou o pai.

Ruan: Não, eu sou pai!

Guilherme: Eu sou o pai!

Ruan: (...) Olhe, dois pais (apontando para Guilherme) e você é a mãe (apontando para Kethely).

Ruan acaricia o cabelo de Kethely duas vezes.

Kethyle levanta-se e deita-se no chão. Ruan acompanha Kethyle dizendo:

Ruan: Dois pais, dois pais! Vamos, dois pais, vamos, dois pais.

Ruan deita-se ao lado de Kethely no chão. Guilherme levanta-se e fica diante deles.

Ruan: Vamos (...) Vamos... na água, na água.

Ruan e Kethely se arrastam pelo chão até a parede da sala. Enquanto isso, Cristofer 


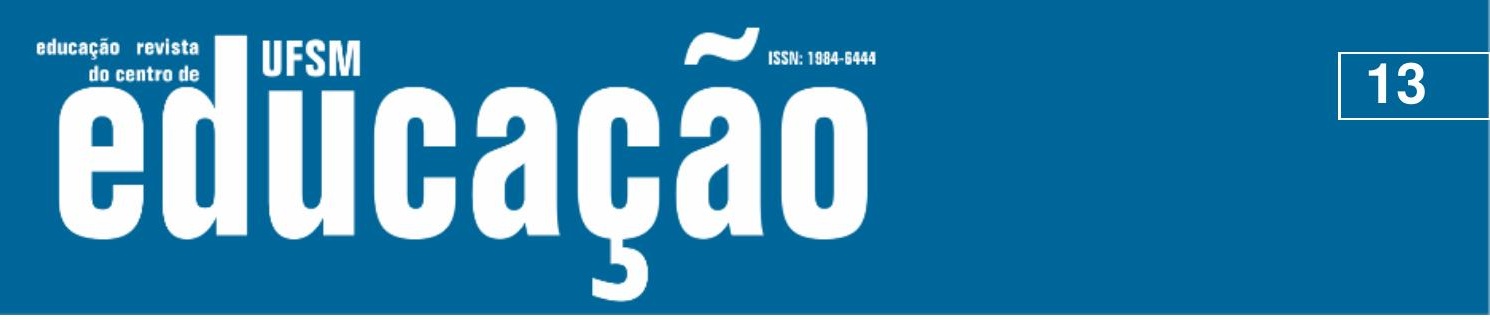

ISSN: 1984-6444 | http://dx.doi.org/10.5902/1984644434956

se aproxima de Guilherme e começam a conversar.

Ruan abraça Kethely. Ela olha para Ruan e eles se abraçam. Sibele à margem da brincadeira, observa os dois por um tempo. Ruan e Kethyle levantam-se. Kethely vai em direção a casinha pegar a boneca e uma toalhinha. Ruan acompanha Kethely. $A$ menina enrola a boneca com a toalhinha enquanto caminha pela sala. Ruan acompanha e sorri.

Cristofer aproxima-se, aponta para Guilherme que está deitado no chão, fingindo de morto. Ao lado de Guilherme tem um brinquedo. Kethely pega o brinquedo e sorri.

Ruan fala para Kethely: O pai vai trabalhar, de novo, já, já (gesticulando com a mão) Cristofer abraça Ruan e Kethely.

Kethely pergunta a Cristofer: Você é amigo dos dois?

Cristofer: Eu sou amigo dele e dele, apontando com o dedo para Kethely e Ruan. Nesse momento, Guilherme, levanta-se do chão, empurra Cristofer e pega o brinquedo de volta. A brincadeira termina quando a cuidadora anuncia que é a hora do lanche.

Figura 1 - Disputa e negociação de papéis

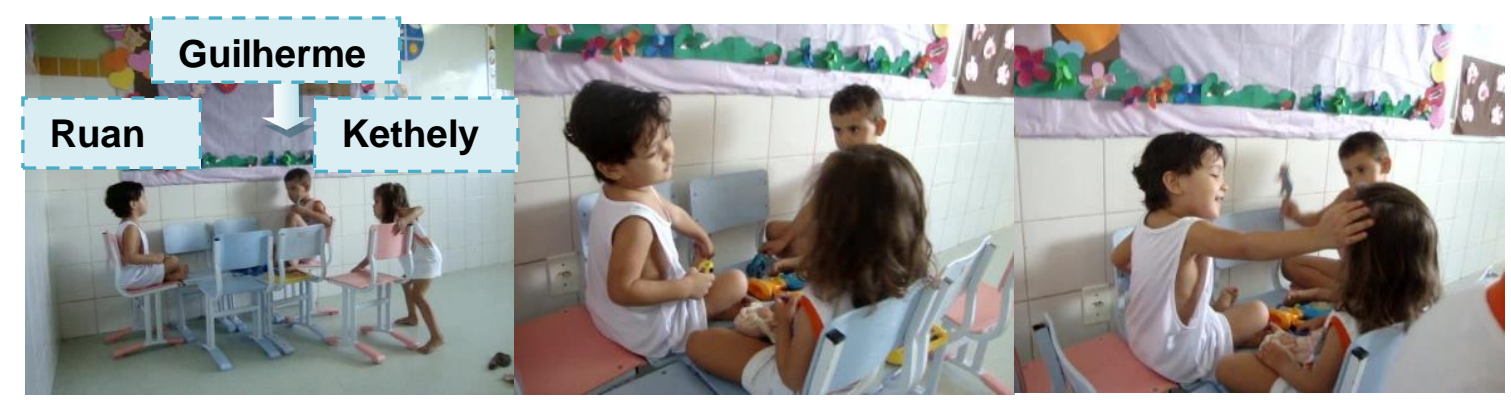

Fonte: Arquivo de pesquisa.

Figura 2 - Reprodução dos papéis de gênero

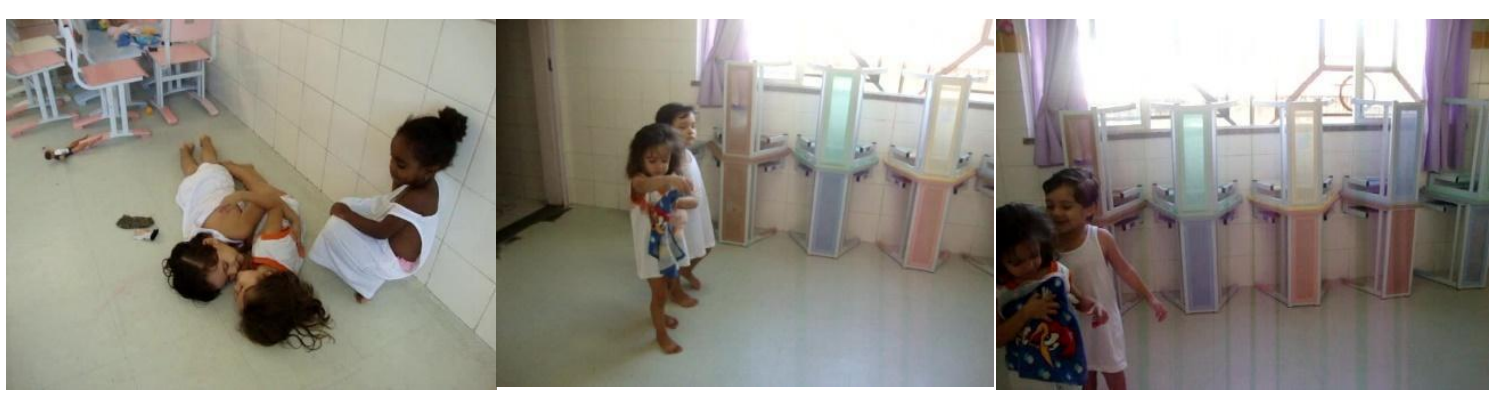

Fonte: Arquivo de pesquisa. 


\section{Autuaŗão}

ISSN: 1984-6444 | http://dx.doi.org/10.5902/1984644434956

Inicialmente, cabe pontuar que a organização espacial das cadeiras da sala nos revela pistas de que o enquadre dado às atividades lúdicas foi a brincadeira de casinha. Durante as observações, presenciamos em diversos momentos essa construção do aglomerado de cadeiras como suporte para a construção da brincadeira ser "de casinha".

Dentro desta perspectiva, percebemos que as crianças integrantes do episódio em destaque não utilizaram os brinquedos disponíveis no ambiente, além da boneca. Assim, a escolha do script esteve relacionada aos usos não convencionais do mobiliário da sala (cadeiras) para a realização das atividades eleitas para compor o tema da brincadeira em curso. Brinquedos como panelinhas, pratos e talheres, fogão, ferro de passar, telefone, dentre outros objetos, sugerem o desenvolvimento de situações que envolvem relações familiares que representam o ambiente e o cotidiano das crianças, embora, tais objetos não forem escolhidos nem ressignificados por elas, transformando-os naquilo que não lhes interessou no momento da brincadeira.

Ao aproximar-se da casinha construída com as cadeiras da sala, Guilherme tem ciência da brincadeira que será desenvolvida pelos companheiros de idade. Esta atitude de Guilherme reforça a ideia de que as crianças possuem um conhecimento prévio que fornece as regras e a estrutura geral de ações e comportamentos que garantem o desenrolar da brincadeira (BORBA, 2005). Sendo assim, em situações de brincadeiras, mesmo com algumas variantes, as crianças demonstram possuir um conhecimento preliminar que Ihes permite desenvolver ações e comportamentos relacionados ao esquema da rotina cultural eleita para constituir a cena lúdica que será compartilhada.

No Episódio "Dois Pais", Ruan inicia a brincadeira com a afirmação de que é o pai e aponta para Kethyle, designando-a como mãe. A garota, ao perceber que tem mais um menino no grupo, indica Guilherme para ser o filho; entretanto, Guilherme não aceita ser o filho e logo reage, contrariando a indicação e afirmando que ele será o pai.

Como se faz notar, há uma disputa pelos papéis adultos, talvez relacionada ao poder reproduzido nas ações das crianças e relações sociais representadas, sobretudo ao maior campo de ação e autonomia na definição e execução das 


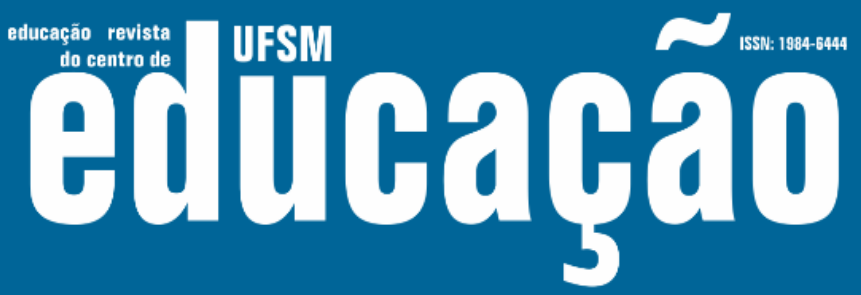

ISSN: 1984-6444 | http://dx.doi.org/10.5902/1984644434956

mesmas, derivado do posicionamento social relacionado a essas identidades representadas: os pais e mães podem fazer mais coisas, mandar, disciplinar, enquanto os filhos devem obedecer, subordinar seus comportamentos às ordens dos pais e mães, por exemplo. Nesse sentido, Corsaro (2009a) explica que

A apropriação e o enriquecimento de modelos adultos pelas crianças se referem primariamente a status, poder e controle. Ao assumir papéis adultos, as crianças adquirem poder (são "empoderadas"). Elas utilizam a licença dramática da brincadeira imaginativa para projetar o futuro - a época em que terão poder e controle sobre si mesmas e sobre os outros (CORSARO, 2009a, p. 34).

Conforme observamos, a definição de papéis entre as crianças encontra um obstáculo quando Guilherme também decide ser pai. Depois de uma tentativa de negociação de papéis não aceita por Guilherme, Ruan propõe que a brincadeira tenha dois pais. O obstáculo é logo transposto com a sugestão de Ruan. Para resolver a situação, reestrutura-se a ideia inicial da brincadeira, duplicam-se os papéis, criando um enredo com dois pais, possibilitando a participação dos interessados na brincadeira. A solução parece agradar a todos, inclusive a Kethyle que não vê nenhum problema em ter dois maridos.

Diante do exposto, Lira (2012) explica que a influência da motivação da criança em vivenciar determinado papel ou desempenhar certa atividade pode ensejá-la a entrar em disputas. Nesse sentido, é preciso destacar que, no grupo de brinquedo, a todo tempo, motivações e interesses de uma criança entram em contato com motivações e interesses de outras e precisam ser equacionados no campo interacional assim circunscrito, de forma a dirimir conflitos.

Reiterando as ideias de Wajskop (2010), ressaltamos que a brincadeira aparece como uma situação organizada, na qual as crianças participam ativamente das decisões que devem ser tomadas em determinados momentos, resolvendo problemas que venham a surgir no desenrolar das práticas lúdicas. Nesse sentido, "mesmo atuando em uma estrutura imaginária, onde as crianças assumem papéis, atribuindo significados diversos às suas ações e aos objetos com os quais interage, na brincadeira, há escolha constante por parte da criança" (WAJSKOP, 2010, p. 36). 


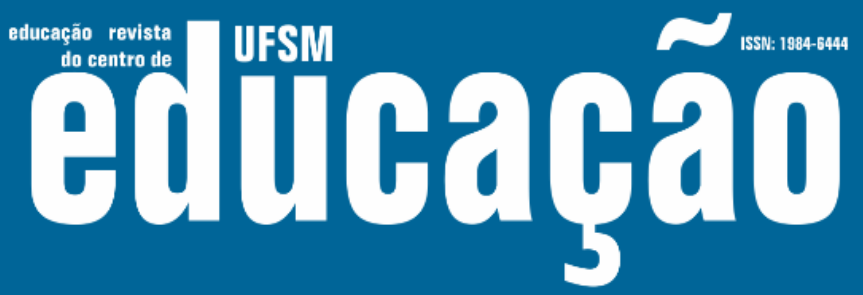

ISSN: 1984-6444 | http://dx.doi.org/10.5902/1984644434956

Nesse sentido, conforme nos relata Brougère (2010), é que ocorre a bidirecionalidade da transmissão cultural, pois as situações de brincadeiras são estruturadas conforme os sistemas de significado cultural do contexto das crianças. Contudo, no desenrolar da brincadeira, a atividade é reorganizada conforme o sentido atribuído pelos participantes, no processo de interação com os pares, segundo seus interesses. Assim, os significados coletivos e individuais são ressignificados no ato de brincar com o outro.

Nesse contexto, no episódio em tela, as crianças utilizam seus conhecimentos acerca das relações familiares, enquanto reproduzem e recriam os elementos de sua cultura, os apreende, levando para o espaço da brincadeira os modelos de comportamentos construídos nas interações vivenciadas nos seus diversos contextos. Estes comportamentos são reconfigurados com a produção de nova significação às relações sociais, com a inclusão de um segundo pai.

O episódio revela indicadores de que por meio da brincadeira, a criança não apenas reproduz as condutas próprias da sua cultura (a condição de se ter um pai), mas as apropria dando um caráter inovador (a condição de se ter dois pais). Essas ações sinalizam que "as crianças não imitam simplesmente modelos adultos nessas brincadeiras, mas antes elaboram e enriquecem continuamente os modelos adultos para atender a seus próprios interesses (CORSARO, 2009a, p. 34).

A ideia de reprodução interpretativa de Corsaro (2009a) pode aqui ser visualizada nas ações sociais das crianças e alinha-se à compreensão aqui defendida de que a criança não se enquadra simplesmente nos costumes do seu contexto sociocultural ou internaliza passivamente valores. No processo de reprodução interpretativa, a criança se apropria, reinventa e reproduz os significados advindos dos diversos processos sociais aos quais se submete.

Nesse sentido, corroboramos com Borba (2005, p. 149), ao afirmar que "a brincadeira não é, portanto, cópia da realidade, mas sim um espaço onde esta é pensada, refletida, discutida, transformada e reinventada, sob os olhos das crianças". Nessa perspectiva, a brincadeira pode ser reconhecida enquanto atividade social e criativa das crianças histórica e socialmente situadas. 


\section{F WEM Eulloahá}

ISSN: 1984-6444 | http://dx.doi.org/10.5902/1984644434956

Na análise do episódio, percebemos como as crianças subvertem as relações parentais por meio da não reprodução de um modelo de família (com apenas um pai). Ao brincar, elas fazem suas escolhas de acordo com aquilo que thes dê prazer, não havendo fronteiras do que é ou não permitido. Sendo assim, as crianças transgridem normas e comportamentos, sendo possível inferir que tais construções sociais são ressignificadas conforme os interesses das crianças nos momentos em que brincam.

Cabe destacar que nos pautamos nas ideias de Paula (2007) para trazer aqui o significado de transgressão das crianças como modos que elas encontram para transpor o que está socialmente convencionado, como o cerne do processo de descoberta, de criação, os quais, coeditam as transformações socioculturais empreendidas ao longo do tempo.

Segundo a autora supracitada, a transgressão não se configura apenas como oposição aos modelos adultos, mas representa a expressão dos desejos, dos sentimentos e dos conhecimentos das crianças que se tornam conteúdos para o repertório imaginativo dos grupos de pares de idade, fazendo-os construir novas maneiras de agir sobre o real do qual fazem parte e alcançar, assim, seus intentos, partilhados com aqueles que se tornam cúmplices de suas criações.

Um outro aspecto a ser considerado no episódio é que apesar de aceitarem a presença de dois pais na brincadeira de papéis, Ruan e Kethely não incluem Guilherme no decorrer da sequência de ações. Este fato pode ser percebido no momento em que Guilherme vê Ruan e Kethyle deitados no chão, encontra Cristofer e começa a brincar com ele, deitando-se no chão, propondo uma nova situação de brincadeira. Entretanto, Cristofer declara ser amigo de Ruan e Kethely e isto faz que que Guilherme se irrite, tome o brinquedo e empurre-o, abandonando o espaço da brincadeira. É possível inferir neste contexto a incompreensão quanto às definições de papéis do "segundo pai", levando Guilherme a desistir da brincadeira.

Na sequência do episódio, Ruan e Kethyle constroem uma brincadeira de faz de conta na qual reproduzem os papéis de gênero de sua cultura: Kethyle, a mãe que cuida do bebê, enquanto Ruan, o pai que sai para trabalhar. A compreensão de pai revelado por Ruan se aproxima daquela em que o pai é o responsável pelo sustento da família, que sai para trabalhar, o responsável pela família. De início, a menina 


\section{Autuaŗão}

ISSN: 1984-6444 | http://dx.doi.org/10.5902/1984644434956

revela sua compressão de mãe, cuidando da boneca.

Os modos de agir de Ruan e Kethely conciliam com as concepções da nossa cultura que associam comportamentos como tipicamente femininos e masculinos. Desse modo, quando uma criança reproduz os papéis de gênero, no jogo de faz de conta, ela estaria se apropriando das representações sociais de gênero que circulam em seu grupo e construindo sua identidade (PEDROSA; SANTOS, 2009).

Borba (2005) ressalta que nas brincadeiras que envolvem papéis familiares, as crianças trazem suas experiências cotidianas e também suas expectativas e concepções sobre como as pessoas, os objetos e as ações se relacionam nesses mundos sociais. Nessas brincadeiras, (papai e mamãe, por exemplo) as crianças dispõem de esquemas que são uma combinação complexa da observação da realidade social (BROUGÈRE, 2015).

Haddad e Maynart (2017), contribuem nesse sentido afirmando que

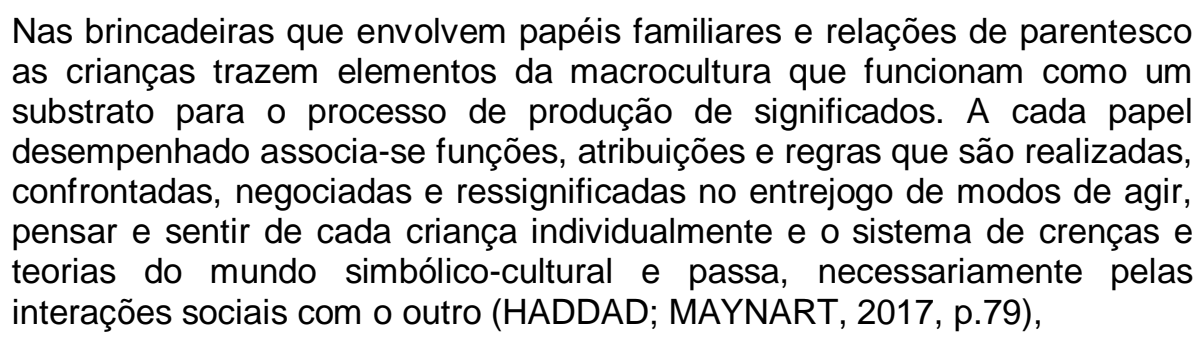

Os dados alçados do episódio apresentado reforçam os achados de outros estudos, tais como aquele desenvolvido por Lira e Pedrosa (2016). Na busca por investigar processos de significação sobre família em brincadeiras de crianças em acolhimento institucional, os autores evidenciaram que as crianças consideram diferentes configurações familiares, explicitam relações horizontais e verticais de seus membros, reafirmam componentes dessas relações como obediência, autoridade e cuidado, bem como vivenciam trocas afetivas.

De todo o exposto, gostaríamos de destacar aqui, corroborando com o argumento de Borba (2005, p. 151), ao defender a perspectiva que "o fato de as crianças assumirem papéis adultos e transporem para as suas brincadeiras, relações familiares e profissionais não significa que a brincadeira deva ser vista como aprendizagem para a vida adulta e para o trabalho." 


\section{Autuaŗão}

ISSN: 1984-6444 | http://dx.doi.org/10.5902/1984644434956

Diante de tais considerações, compreendemos o brincar como uma prática social e cultural, na qual as crianças constroem suas relações sociais e formas individuais e coletivas de interpretarem o mundo, enfatizando-se a agência das crianças nas suas relações com seu contexto social.

\section{Apontamentos finais}

Em linhas gerais, os dados gerados neste trabalho permitem constatar que, em situações de brincadeiras, as crianças constroem, negociam e compartilham significados, indicando compreensões sobre papéis sociais desempenhados no cotidiano familiar. No faz de conta envolvendo relações familiares, as crianças sinalizaram fragmentos perceptivos/interpretativos a respeito desse contexto social, confirmando resultados de outros estudos.

Nas brincadeiras que envolvem papéis familiares, as crianças participantes protagonizam experiências sobre o que acontecem nos seus cotidianos, compartilham conhecimentos, criam regras e enredos para brincadeiras e demonstram suas compreensões acerca da construção de significados dos papéis sociais dos integrantes familiares, como mãe e pai.

Por meio da brincadeira de faz de conta as crianças utilizam seus conhecimentos acerca das relações familiares, enquanto (re)produzem os elementos de sua cultura, os apreende e legitima, levando para o espaço da brincadeira os modelos de comportamentos construídos nas interações vivenciadas nos seus diversos contextos.

As crianças também extrapolam o real instituído, a partir de seus interesses, criando um campo de possibilidades de ação, de renovação e recriações do contexto sociocultural que observa.

O estudo aponta indicadores de que por meio da brincadeira, a criança não apenas reproduz as condutas próprias da sua cultura, mas apropria-se dela dando um caráter inovador, reconfigurando comportamentos sociais com a produção de nova significação às relações sociais quando transgridem padrões e permitem a existência de dois pais no contexto familiar. 


\section{- Tusm EItlagha}

ISSN: 1984-6444 | http://dx.doi.org/10.5902/1984644434956

Sendo assim, os resultados se alinham com estudos que defendem a ideia sobre o brincar considerado um espaço privilegiado para a investigação das relações dos mundos sociais das crianças. Desta forma, através dos processos interativos, as crianças revelam sua capacidade de agir socialmente entre pares, de compartilhar significações, regras e valores, confirmando a ideia de que elas são socialmente ativas e protagonistas do mundo social.

Tais resultados nos revelam contribuições importantes para o campo da educação infantil. O estudo permite maior visibilidade para as brincadeiras espontâneas das crianças, criadas e organizadas por elas, haja vista que tais práticas sociais muitas vezes nem são observadas, acompanhadas e analisadas pela/o professor/a em muitas instituições de Educação Infantil.

O brincar no contexto da Educação Infantil, como elucidado nessa investigação, se caracteriza como um importante espaço de experiências de aprendizagens onde as crianças compartilham significados e recriam situações sociais que observam para além dos conteúdos escolares. Quando intencionalmente organizados pelo/a professor/a, através da disponibilidade de tempos, espaços e materiais para as crianças interagir, os momentos de atividades lúdicas compartilhadas também potencializam a vivência de experiências de infância, de cultura que reconhecem o protagonismo e a agência das crianças desde os primeiros anos de vida.

\section{Referências}

ALDERSON, Priscilla. As crianças como pesquisadoras: os efeitos dos direitos de participação sobre a metodologia de pesquisa". Revista Educação e Sociedade, Campinas, v. 26, n. 91, p. 419-442, Maio/ago. 2005. Disponível em: http://www.cedes.unicamp.br. Acesso em: 14 fev. de 2016.

BORBA, Angela Meyer. Culturas da infância nos espaços-tempos do brincar. 2005. 296f. Tese (Doutorado em Educação) - Universidade Federal Fluminense, Niterói, 2005.

BROUGÈRE, Gilles. A crianças e a cultura lúdica. In: KISHIMOTO, Tizuko Morchida (org.). O brincar e suas teorias. São Paulo: Cengage Learning, 2015. p. 19-32.

BROUGÈRE, Gilles. Brinquedo e cultura. 8.ed. São Paulo: Cortez, 2010. (Coleção questões da nossa época; v.20). 


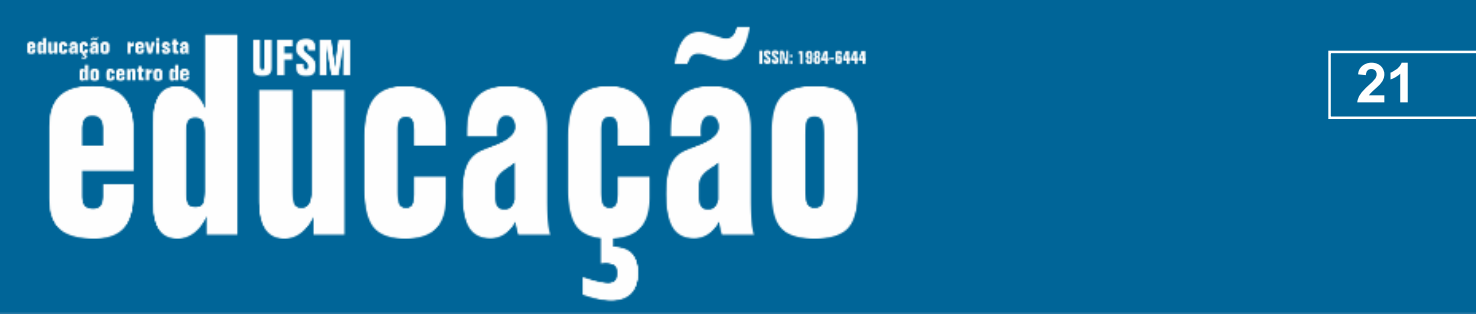

ISSN: 1984-6444 | http://dx.doi.org/10.5902/1984644434956

COHN, Clarice. Antropologia da criança. Rio de Janeiro: Ed. Jorge Zahar, 2005.

CORSARO, William A. Reprodução interpretativa e cultura de pares. In: MÜLLER, Fernanda; CARVALHO, Ana Maria Almeida (orgs.). Teoria e prática na pesquisa com crianças: diálogos com William Corsaro. São Paulo: Cortez, 2009a. p. 31-50.

CORSARO, William. Métodos Etnográficos no estudo da cultura de pares e das transições iniciais na vida das crianças. In: MÜLLER, Fernanda; CARVALHO, Ana Maria Almeida (Orgs.). Teoria e prática na pesquisa com crianças: diálogos com William Corsaro. São Paulo: Cortez, 2009b. p. 83-103.

CORSARO, William. Sociologia da Infância. Porto Alegre: Artmed, 2011.

FERREIRA, Manuela. Do "avesso" do brincar ou... as relações entre pares, as rotinas da cultura infantil e a construção da(s) ordem(ens) social (ais) instituinte(s) das crianças no jardim-de-infância. In: SARMENTO, Manuel Jacinto; CERISARA, Ana Beatriz (Orgs.). Crianças e miúdos. Perspectivas sócio-pedagógicas da infância e educação. Porto: Asa, 2004.

GRAUE, Elisabeth; WALSH, Daniel. Investigação etnográfica com crianças: teorias, métodos e ética. Lisboa: Fundação Calouste Gulbenkian, 2003.

HADDAD, Lenira; MAYNART, Renta da Costa. A compreensão de relações familiares pelas crianças em situação de brincadeira em contexto de educação infantil. Revista Zero-a-seis. Florianópolis, v. 19, n. 35, p. 69 - 81, jan-jun. 2017. Disponível em: https://periodicos.ufsc.br/index.php/zeroseis. Acesso em: 11 de jan. 2017.

KRAMER, S. Autoria e autorização: questões éticas na pesquisa com crianças. Cadernos de Pesquisa, n.116, p.41-59, julho/2002.

LIRA, Pedro Paulo Bezerra de. Processos de significação sobre famílias acolhidas institucionalmente.165f. Dissertação (Mestrado em Psicologia) -- Universidade Federal de Pernambuco, Recife, 2012. Disponível em: https://repositorio.ufpe.br/handle/123456789/8738. Acesso em: 10 de Jan. 2017.

LIRA, Pedro Paulo Bezerra de; PEDROSA, Maria Isabel. Processos de Significação sobre Família em Brincadeiras de Crianças em Acolhimento Institucional. Psicologia: Teoria e Pesquisa. Brasília, v. 32 n. 3, p. 1-9, jul-set. 2016. Disponível em: http://www.scielo.br/pdf/ptp/v32n3/1806-3446-ptp-32-03-e323214.pdf. Acesso em: 29 de jan. 2018.

LUCENA, Juliana M. Ferreira; PEDROSA, Maria Isabel. Estabilidade e transformação na construção de rotinas compartilhadas no grupo de brinquedo. Psychology/Psicologia Reflexão e Crítica, Porto Alegre, 27(3), p. 556-563. 2014. Disponível em: http://www.scielo.br/pdf/prc/v27n3/0102-7972-prc-27-03-00556.pdf. Acesso em: 29 de jan. 2018.

OLIVEIRA, Zilma M. Ramos. Jogo de papéis: Um olhar para as brincadeiras infantis. São Paulo: Cortez, 2011. 


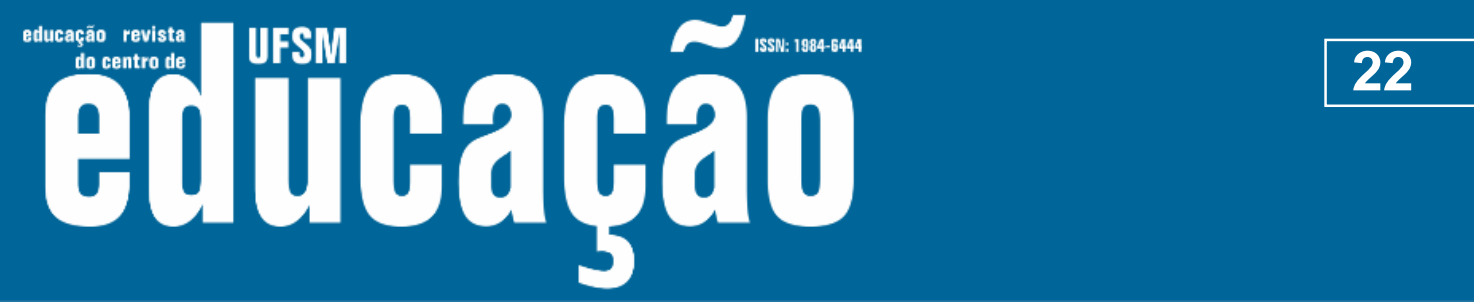

ISSN: 1984-6444 | http://dx.doi.org/10.5902/1984644434956

PAULA, Elaine de. Deu, já brincamos demais!. As vozes das crianças diante da lógica dos adultos na creche: transgressão ou disciplina?. Dissertação (Mestrado em Educação), 168f, Universidade Federal de Santa Catarina, 2007.

PEDROSA, Maria Isabel. CARVALHO, Ana Maria Almeida. Análise qualitativa de episódios de interação: uma reflexão sobre procedimentos e formas de uso. Revista Psicologia: Reflexão e Crítica, Porto Alegra, 18(3), p.431-442. 2005. Disponível em: http://www.scielo.br/pdf/prc/v18n3/a18v18n3.pdf. Acesso em: 10 de Jan. 2016.

PEDROSA, Maria Isabel. SANTOS, Maria de Fátima. Aprofundando reprodução interpretativa e cultura de pares em diálogos com Corsaro. In: Teoria e prática na pesquisa com crianças: diálogos com William Corsaro. MULLER, Fernanda. CARVALHO, Ana Maria Almeida (Orgs.). São Paulo: Cortez, 2009, p.51-58.

PEREIRA, Melina C.; LIRA, Pedro Paulo Bezerra; PEDROSA, Maria Isabel. Observando brincadeiras e conversando com crianças sobre família. In: MOREIRA, Lúcia Vaz de Campos; RABINOVICH, Elaine Pedreira. (Orgs.). Família e parentalidade: olhares da psicologia e da história. Curitiba: Juruá, 2011, p. 41-62.

ROCHA, Sergio Lizias Costa de Oliveira. As multiplicidades de discurso de gênero, através das práticas lúdicas, no contexto da educação infantil. In: COSTA, Maria de Fátima Vasconcelos da; COLAÇO, Veriana de Fátima Rodrigues; COSTA, Nelson Barros da.(Orgs.). Modos de brincar, lembrar e dizer: discursividade e subjetivação. Fortaleza: Edições UFC, 2007.

SANTOS, Carina Pessoa. Ontogênese das representações sociais de família em crianças de quatro a seis anos. 224f. Tese (Doutorado em Psicologia) Universidade Federal de Pernambuco, Recife, 2015. Disponível em: https://repositorio.ufpe.br/bitstream/123456789/14964/1/2015_Tese_Carina.pdf. Acesso em: 25 de Jan. 2017.

SARMENTO, Manuel Jacinto. Imaginário e culturas da infância, 2003. Disponível na Internet: http:www.iec.minho.pt/cedic/textos de trabalho. Acesso em: 30 de maio. 2016.

SPINK, Mary J.P. A ética na pesquisa social: da perspectiva prescritiva à interanimação dialógica. EDIPCS. Revista semestral da Faculdade de Psicologia PUC-RS, Porto Alegre, v. 31, n. 1, p. 7-22, Jan/Jul, 2000. Acesso em: 24 jan. de 2016.

WAJSKOP, Gisela. O brincar na Educação Infantil: uma história que se repete. 9.ed. São Paulo: Cortez, 2010. 


\section{N

ISSN: 1984-6444 | http://dx.doi.org/10.5902/1984644434956

\section{Correspondência}

Rafaely Karolynne do Nascimento Campos - Universidade Federal de Sergipe Cidade Universitária Prof. José Aloísio de Campos - Av. Marechal Rondon, s/n, Jardim Rosa Elze, CEP 49100-000 - São Cristóvão, Sergipe, Brasil.

\section{(c) $)$ (i) (8)}

This work is licensed under a Creative Commons Attribution-NonCommercial 4.0 International (CC BY-NC 4.0)

\section{Notas}

\footnotetext{
${ }^{1}$ Utilizamos as seguintes convenções para as transcrições dos episódios: Palavras em negrito indicam ênfase; (...) indica pausa na fala; (---) indica trecho incompreensível; Períodos entre parênteses tem a função de explicar o contexto da fala.
} 